\title{
A Auto-Avaliação nos Projectos EQUAL
}

\author{
David Figueiroa ${ }^{*}$ \\ Manuel Pimenta ${ }^{* *}$
}

\begin{abstract}
$\mathrm{R}$ Resumo: Este artigo apresenta as linhas gerais do modelo de avaliação proposto pela Gestão do Programa EQUAL às Parcerias de Desenvolvimento $(\mathrm{PD})$ que executam projectos experimentais no combate às discriminações no mercado de trabalho financiados pelo programa, e apresenta uma reflexão sobre a experiência de operacionalização dos dispositivos de avaliação e sobre a realização e os resultados dos exercícios de auto-avaliação dos projectos, sublinhando os principais méritos e dificuldades das soluções construídas pelas PD e as potencialidades do modelo proposto.
\end{abstract}

Palavras-Chave: avaliação; auto-avaliação; avaliação independente; reflexão participada; Programa EQUAL; parcerias de desenvolvimento.

\section{Introdução}

O Programa de Iniciativa Comunitária EQUAL, em vigor no período de programação dos Fundos Estruturais 2000-2006 - sucedendo às Iniciativas Comunitárias EMPREGO e ADAPT (1994-1999) - é co-financiado pelo Fundo Social Europeu e pelo Estado Português e visa promover novas práticas de luta contra as discriminações e desigualdades de qualquer natureza relacionadas com o mercado de trabalho.

O Programa EQUAL tem a ambição de estimular respostas de vanguarda na luta contra as discriminações e a exclusão social, reclamando inovação onde a renovação das políticas e das práticas é especialmente necessária e pertinente, mas, também, particularmente difícil (sobretudo ao nível da generalização das boas práticas, no sentido da sua eficácia junto dos beneficiários): o campo da intervenção de apoio aos grupos mais desfavorecidos e marginalizados ${ }^{1}$.

O Programa assume uma grande amplitude ao nível da sua intervenção, cruzando medidas de carácter preventivo e de carácter reparador (IED, 2005:13) e reclamando uma vocação "estruturante" (Gabinete de Gestão EQUAL, 2004 a):9), no sentido em que pretende promover mudanças nos "sistemas", acrescentando valor:
- às práticas e aos processos de inserção no mercado de trabalho, na óptica da melhoria da sua qualidade e adequação aos públicos-alvo;

- às organizações envolvidas nas Parcerias de Desenvolvimento (PD), nomeadamente, às estruturas de formação e às próprias empresas, contribuindo para a sua especialização e inovação e para o reforço das competências técnicas de formadores e outros agentes;

- às políticas de emprego e formação profissional e às políticas sociais.

O EQUAL é, a todos os títulos, muito ambicioso e exigente, o que se revela não só nos seus objectivos e abordagens "estratégicas" mas também nos requisitos "instrumentais" e "metodológicos" que impõe aos projectos por ele financiados, e que devem ser incorporados desde a fase de concepção à conclusão (desejavelmente, à "pós-conclusão", numa óptica de perenidade e sustentabilidade futuras do modelo de intervenção que propõe). O EQUAL elegeu assim um conjunto de princípios/requisitos que, tomados em conjunto, constituem a especificidade da sua proposta: $o$ trabalho em parceria (desde logo potenciado pela constituição das Parcerias de Desenvolvimento que promovem os projectos), a cooperação transnacional, o empowerment, a igualdade de género e a inovação e sua disseminaçã॰/mainstreaming.

* Psicólogo, responsável pela avaliação, informação e comunicação no Gabinete de Gestão EQUAL. Contacto: dfigueiroa@equal.pt

** Sociólogo, consultor externo do Gabinete de Gestão do EQUAL. Contacto: mpimenta@equal.pt

Quer a pertinência quer as dificuldades, foram, ainda, reforçadas nos últimos anos, face à evoluçāo do contexto socioeconómico (crise económica, aumento do desemprego). 
Neste quadro de exigência acrescida face aos programas e práticas precedentes (um quadro inovador na sua especificidade), a avaliação das intervenções adquire, também, uma importância acrescida. Esta importância é transversal aos diversos níveis de análise (europeu, nacional, regional, local), mas é, sem dúvida, no quadro da implementação de cada projecto - encarado enquanto "laboratório experimental" de novas ideias e intervenções - que a avaliação adquire uma relevância e uma utilidade que a tornam indispensável. A avaliação é, assim, coerentemente considerada "uma dimensão estratégica de um projecto EQUAL, um pilar de um projecto experimental e inovador" (Gabinete de Gestão EQUAL, 2004 a):49).

No sentido de facilitar o processo, clarificando os seus princípios, filosofia e objectivos, a Gestão do Programa promoveu iniciativas de apoio à avaliação dos projectos: publicação de textos enquadradores (Gabinete de Gestão EQUAL, 2004a):49-53), publicação de guias para a auto-avaliação e para balanço de competências ${ }^{2}$ e de guias para a elaboração, caracterização e validação de produtos $^{3}$, realização de sessões de esclarecimento e debate com especialistas ${ }^{4}$, concepção de um dispositivo para apoio e informação ${ }^{5}$, definição de um quadro de referência para o apoio à contratação de entidades e peritos externos pelos projectos para a realização de uma avaliação "independente" .

As iniciativas de orientação e suporte aos projectos não restringem, no entanto, o espaço que cada projecto deve assumir na especificidade da sua própria avaliação, quer a nível dos conteúdos, quer a nível das metodologias. Cabe, portanto, a cada Parceria de Desenvolvimento (PD) definir e executar, numa lógica de flexibilidade, a sua própria estratégia de avaliação, tendo como referência enquadradora (mas não "exclusivista") as orientações e os instrumentos/guias disponibilizados pelo EQUAL.
Na fase actual de desenvolvimento do Programa já é possível reflectir sobre o lugar e o papel estratégico da avaliação, como factor de qualidade dos projectos e da inovação produzida. Este artigo pretende apresentar as linhas gerais do modelo de avaliação proposto às $\mathrm{PD}$ pela Gestão do Programa e reflectir sobre a experiência de operacionalização dos dispositivos de avaliação ao nível dos projectos, sublinhando os principais méritos e dificuldades das soluções construídas pelas PD.

\section{Os projectos EQUAL}

O EQUAL valoriza projectos de verdadeira vocação experimental (associada à inovação) e de tipo "estruturante" e com potencial de disseminação, capazes de influenciar positivamente os "sistemas" e as "soluções" convencionais. Os projectos constituem um processo dinâmico e evolutivo cujo desenvolvimento passa pela execução de três "Acções", correspondentes a outros tantos momentos de candidatura e selecção.

Em Portugal, a primeira fase de execução do programa teve início em 2001, desde logo com a "Acção 1", que corresponde a uma etapa preparatória, com um máximo de 6 meses de duração, para aprofundar o diagnóstico de necessidades e estabelecer a Parceria de Desenvolvimento nacional e a Parceria Transnacional. A etapa seguinte, a "Acção 2", com uma duração média de 2 anos, corresponde à fase de desenvolvimento do projecto e dos "produtos" inovadores, podendo estes corresponder a recursos técnico-pedagógicos originais ou a práticas bem sucedidas - isto é, para além dos produtos clássicos, que correspondem a novos recursos construídos pela acção dos projectos, valorizam-se igualmente os "processos" que trazem valor acrescentado às práticas vigentes - e que são sistematizados em "narrativas" tangíveis, que facilitam o seu conhecimento, a disseminação e a apropriação por terceiros.

\footnotetext{
2 Auto-avaliação dos Projectos - 2. ${ }^{\text {a }}$ Fase (Gabinete de Gestão EQUAL, 2005) e Balanço de Competências (Madalena Estevão, 2005).

${ }^{3}$ Recursos Técnico-Pedagógicos \& Práticas Bem Sucedidas (Horácio Covita, 2003) e Produtos EQUAL: Validar para Disseminar (coord. Gabinete de Gestão EQUAL, 2005).

4 Concentradas em 2002 (projectos da $1 .^{\mathrm{a}}$ Fase) e em 2005 (projectos da 2. ${ }^{\mathrm{a}}$ Fase)

5 Através da página da internet (www.equal.pt) e da criação de um endereço electrónico para questões de avaliação.

"Avaliação "independente", como avaliação externa (realizada por entidade externa à Parceria) ou interna (quando a entidade avaliadora integra a Parceria, mas a equipa de avaliação é "externa" à equipa implicada na execução do projecto). Cfr. Avaliação independente dos Projectos EQUAL - Orientações (Gabinete de Gestão EQUAL, 2005, policopiado).
} 
A “Acção 2" conclui-se com a validação dos produtos (validação pelos pares, por peritos e pelos potenciais utilizadores $)^{7}$. Os produtos validados são objecto de disseminação na "Acção 3"8.

Presentemente, a generalidade dos projectos da primeira fase da EQUAL encontram-se a executar a "Acção 3", correspondente à etapa de disseminação dos "produtos" inovadores concebidos, produzidos, testados e validados no decurso da "Acção 2" pelas Parcerias de Desenvolvimento formadas na "Acção 1", em número superior a uma centena. A segunda fase do Programa (novo ciclo de “Acções 1, 2 e 3") arrancou em 2005 e os projectos aprovados (pouco menos de uma centena) já se encontram actualmente no terreno a executar a "Acção 2".
A nível temático, o EQUAL organiza-se em cinco "prioridades" e doze "áreas de intervenção", que enquadram os projectos propostos e realizados pelas Parcerias de Desenvolvimento. Estas, de natureza predominantemente regional ou sectorial, são compostas, em média, por 7 entidades $^{9}$, que devem ser complementares no seu "posicionamento" no terreno, na sua "vocação", no seu know-how, nas suas intervenções. A relevância de cada parceiro para responder ao problema e às necessidades diagnosticadas e a exploração das complementaridades possíveis, permitem promover e rentabilizar recursos (de diverso tipo) e adequar as respostas, cada vez mais integradas, às exigências dos beneficiários finais e da sociedade inclusiva.

Quadro 1 - Prioridades e Áreas de intervenção do Programa EQUAL

1. Empregabilidade

3. Adaptabilidade para as mulheres e os homens

5. Requerentes de asilo
1.1.1. Percursos integrados de orientação-formação-inserção

1.2.1. Prevenção de discriminações raciais e étnicas

2.1.1. Criação de empresas e desenvolvimento local

2.2.1. Qualificação das organizações e dos profissionais da economia social

3.1.1. Formação ao longo da vida: a formação em contexto de trabalho

3.2.1. Adaptação e reconversão profissional

3.2.2. Modernização e inovação organizacional

3.2.3. Cidadania empresarial - economia cívica

3.2.4. Sociedade da informação e do conhecimento

4.1.1. Conciliação vida familiar/ vida profissional

4.2.1. Eliminação da discriminação no trabalho

5.1.1. Formação e integração profissional e social dos requerentes de asilo

Fonte: Guia de Apoio ao Utilizador - 2. ${ }^{\mathrm{a}}$ Fase (Gabinete de Gestão EQUAL, 2004).

\footnotetext{
Cfr. Produtos EQUAL: Validar para Disseminar (coord. Gabinete de Gestão EQUAL, 2005).

${ }^{8}$ Cfr. Guia de Apoio ao Utilizador - Acção 3 (Gabinete de Gestão EQUAL, 2004).

9 A média de entidades por PD na Acção 2 da primeira fase foi de 7. Na mesma Acção da segunda fase, a média é de 6 (Ponto de Situação da Execução, Gabinete de Gestão EQUAL, 2005, policopiado).
} 


\section{A avaliação nos projectos EQUAL - princípios e características}

Nunca, como na EQUAL, se foi tão longe nas exigências colocadas a projectos de intervenção social no capítulo da avaliação e, em particular, da auto-avaliação, produzindo orientações e instrumentos de apoio, promovendo a formação, encorajando e patrocinando o investimento na avaliação $^{10}$. O EQUAL procurou inovar neste domínio e apostar na difusão de uma cultura de avaliação e de responsabilidade colectiva, constituindo neste aspecto, provavelmente, uma prática com potencial de disseminação.

Tal como se afirma no guia para a auto-avaliação dos projectos EQUAL (2005), um projecto experimental e inovador, que se desenvolve de forma dinâmica e evolutiva, tem na avaliação um dos seus pilares fundamentais, permitindo assegurar internamente o rigor e a qualidade do processo e dos resultados e, externamente, a credibilidade do projecto. A avaliação é, assim, encarada como um instrumento de gestão e de aprendizagem colectiva, "uma constante interrogação sobre todo o ciclo de desenvolvimento do projecto, desde a concepção e planeamento até à operacionalização e execução das actividades" (Auto-avaliação dos projectos, 2003:12).

O EQUAL, enquanto "laboratório de experimentação" de práticas inovadoras no combate às desigualdades e discriminações no mercado de trabalho, propõe um modelo de projecto flexível e interactivo, o que implica que se criem mecanismos de auto-regulação permanente que permitam assegurar e actualizar, ao longo do processo, a pertinência e a coerência do projecto, introduzindo as correcções e os ajustamentos necessários à melhoria contínua da sua qualidade e eficácia, contribuindo para a produção de inovação e para a transferência de recursos técnico-pedagógicos e de práticas bem sucedidas, objectivo último da acção dos projectos.
As orientações presentes nos documentos já referidos não constituem "receitas" nem prescrições rígidas, a aplicar acriticamente, pelo contrário, são uma referência a ter em conta que deve ser apropriada de forma criativa. Por exemplo, a referência de base para a auto-avaliação é um guião com um conjunto de questões que são um denominador comum para todos os projectos, mas que, desejavelmente, constitui apenas um subconjunto das questões pertinentes que cada projecto deve colocar a si próprio, em função da sua realidade específica. Neste sentido, as Parcerias de Desenvolvimento têm a oportunidade e a responsabilidade de conceber a sua própria estratégia e plano de avaliação, à medida das suas necessidades, com incidência em todas as etapas do ciclo de desenvolvimento do seu projecto, focalizado nos processos e nos resultados da intervenção. Sendo assim, e tal como o desenvolvimento do projecto é um contínuo (dinâmico) no tempo, também os exercícios de avaliação o devem ser. Ao nível da auto-avaliação, foram estabelecidos, no entanto, três momentos para a sistematização dos resultados do exercício - no início, numa fase intercalar e no final da implementação do projecto. Não há, porém, qualquer contradição real com o estabelecimento de um exercício "contínuo" (que atenda às dinâmicas e acontecimentos fundamentais do projecto) de auto-avaliação, há apenas momentos predefinidos para a sistematização da reflexão e dos resultados apurados ao longo do processo.

A nível metodológico, estimula-se, igualmente, um espaço de inovação e criatividade, balizada por princípios gerais inerentes à "qualidade" do processo, tais como: a combinação de metodologias e técnicas "quantitativas" e "qualitativas", que dêem conta da singularidade dos processos, dos resultados, das práticas inovadoras e dos recursos técnico-pedagógicos elaborados pelos projectos; o estabelecimento de "processos" dinâmicos de avaliação em detrimento de "momentos" estanques

\footnotetext{
${ }_{10}$ De entre os documentos produzidos pelo Gabinete de Gestão EQUAL para enquadramento dos exercícios de avaliação destacam-se dois instrumentos: o guia para a Auto-avaliação dos Projectos (Gabinete de Gestão EQUAL, 2003) - e a sua versão revista Auto-avaliação dos Projectos - 2. ${ }^{\text {a }}$ Fase (Gabinete de Gestão EQUAL, 2005) - e o documento Avaliação independente dos Projectos EQUAL - Orientações (Gabinete de Gestão EQUAL, 2005, policopiado). O primeiro tem por finalidade melhorar as capacidades das PD nos domínios do planeamento participado, da gestão racional e da abertura à participação, da gestão racional e da abertura à participação e inovação e apresenta-se como um instrumento para dinamizar o processo de auto-avaliação; inclui um Guião que propõe um conjunto de dimensões e questões de avaliação e pretende estimular o acompanhamento e a reflexão estratégica ajudando as parcerias a melhorar a sua intervenção; o segundo fornece um conjunto de orientações para as PD organizarem o processo de contratação da avaliação independente e pretende contribuir para melhorar a qualidade e utilidade dos exercícios de avaliação.
} 
de avaliação; a priorização de dimensões estratégicas e essenciais como objecto de análise aprofundada em detrimento de uma avaliação extensiva (inapropriada face à complexidade e multidimensionalidade dos projectos); a reflexão partilhada pelos diversos actores envolvidos nas diferentes dimensões do projecto (em relação directa com a "pertinência" do seu envolvimento, em função do objecto da avaliação e da etapa da avaliação em causa).

De facto, um princípio-base da avaliação EQUAL, em coerência com a filosofia do programa, é o da participação de todos os agentes envolvidos na intervenção, em particular os públicos-alvo e todos os demais agentes e pessoas que, directa ou indirectamente, estejam implicados no projecto ou beneficiem das actividades realizadas e cuja perspectiva seja pertinente para a compreensão do processo, identificação e avaliação dos resultados. Neste entendimento, sublinha-se o facto de a avaliação ser para os participantes um factor de empowerment e, para os projectos, um mecanismo de auto-regulação que visa a sua qualidade, desenvolvimento e aprofundamento contínuos. A avaliação EQUAL deve ser contínua, formativa e sumativa.

Propõe-se um dispositivo de avaliação misto, que conjuga dois tipos de avaliação: a auto-avaliação, que, envolvendo todos os actores "pertinentes" directamente implicados na execução do projecto, promove a reflexão (auto)-crítica da Parceria de Desenvolvimento; e a avaliação "independente", que é da responsabilidade de um avaliador "externo", contratado para o efeito, ou de um elemento "interno" à parceria mas com autonomia face à equipa que executa das actividades - a "independência" traduz, pois, uma visão externa (no mínimo) face à equipa executora do projecto.

Assim, no primeiro caso, os resultados obtidos expressam exclusivamente o juízo da PD sobre o seu trabalho (mesmo quando o exercício é assistido ou dinamizado por um avaliador independente). No segundo caso, o resultado traduz a perspectiva autónoma do avaliador independente (ainda que formada, muitas vezes, sobre as perspectivas cruzadas dos actores pertinentes em cada questão de avaliação).

Encaram-se estes diferentes olhares ou perspectivas como complementares e não como alternativos: trata-se da complementaridade do olhar do sujeito sobre si próprio $e$ do olhar do outro. Só assim se estabelece e reforça a identidade do sujeito (da intervenção), articulando-se desejável e inexoravelmente a percepção própria e a do outro (uma sem a outra, ou uma predominante sobre a outra, prejudicaria o equilíbrio e a consolidação dessa identidade), que se podem traduzir, tendencialmente, pela auto-avaliação $e$ pela avaliação externa.

Em qualquer dos casos, os processos e os resultados a que se chega (a que se vai chegando) devem ser, em primeiro lugar, úteis (e, logo, em tempo útil) para o sujeito da intervenção (genericamente, as Parcerias de Desenvolvimento), contribuindo para um melhor conhecimento e aprofundamento do projecto e das suas dinâmicas e resultados. Secundariamente, constituem inputs para as avaliações que se realizam a nível "supra-projecto", quer seja no plano regional ou sectorial, nacional ou europeu. Esta dimensão implica um rigoroso alinhamento com as etapas de execução dos projectos, de forma a fornecer informação para alimentar a reflexão estratégica e operacional.

Independentemente da opção tomada no que respeita à avaliação independente (externa ou interna à Parceria - mas sempre externa à equipa técnica de execução), deve promover-se uma estreita articulação entre a auto-avaliação e a avaliação independente, as quais devem conjugar-se, igualmente, no âmbito de uma estratégia integrada, com outros instrumentos de gestão e avaliação dos projectos, em particular com os já referidos balanços de competências e processos de validação de produtos (requisitos obrigatórios dos projectos), cujos resultados permitirão, no final da "Acção 2", demonstrar os resultados e a inovação produzida. Apesar destes últimos instrumentos poderem ter aplicação autónoma, deve prever-se o seu alinhamento com as etapas da auto-avaliação e avaliação independente de forma a constituírem inputs para estas (e vice-versa). A articulação horizontal da auto-avaliação com os referidos instrumentos, permite aprofundar dimensões fundamentais dos projectos como o valor acrescentado em termos de aquisição de competências dos actores envolvidos, da qualidade da inovação produzida e do potencial de disseminação dos produtos validados. 
A operacionalização de uma estratégia de avaliação e a realização articulada dos diferentes exercícios de avaliação e balanço de competências e da validação dos produtos, supõe que os projectos organizem, paralelamente, um sistema de acompanhamento/monitorização para assegurar, atempadamente, os indicadores pertinentes (de realização e de resultados) que permitam recolher e tratar a informação sobre as realizações e os resultados, as práticas e os produtos desenvolvidos. Deve ser estreita a relação entre acompanhamento e avaliação, pois são peças-chave do processo de inovação e da criação de parcerias organizadas e consolidadas. O acompanhamento assegura as informações necessárias à boa gestão e execução das actividades e é um recurso fundamental para a avaliação, devendo ser desenhado para cumprir este objectivo.

Quadro 2 - Dispositivo de avaliação de um projecto EQUAL:

Dinamização da avaliação independente (externa / interna à PD) e da auto-avaliação

Equipa responsável pela condução do exercício

\section{Avaliação externa ou interna}

1.A - A avaliação é conduzida por um avaliador externo contratado para o efeito (avaliação externa), cabendo-lhe a responsabilidade final pelo relatório da avaliação.

O relatório da avaliação externa pode

Equipa externa à PD

Equipa interna à PD integrar parte das dimensões e variáveis sugeridas no "Guião da auto-avaliação" e utilizar os resultados da auto-avaliação como input para a avaliação externa.

Os resultados finais apurados da avaliação externa, traduzirão, em qualquer caso, a perspectiva autónoma do avaliador e não a da PD.

1.B - Em alternativa à avaliação externa, a PD pode optar por designar um avaliador interno com autonomia face à equipa de projecto (avaliação interna).

O relatório da avaliação interna pode integrar parte das dimensões e variáveis sugeridas no "Guião da auto-avaliação" e utilizar os resultados da auto-avaliação como input para a avaliação interna.

Os resultados finais apurados da avaliação interna, traduzirão, em qualquer caso, a perspectiva autónoma do avaliador e não a da PD.

\section{Auto-avaliação}

2.A - O processo de auto-avaliação é dinamizado por um avaliador externo. Pode utilizar-se um "modo de reflexão" que consiste no avaliador externo propor respostas à Parceria (em especial se já possuir dados sobre as matérias em questão resultantes do desenvolvimento do estudo de avaliação externa).

Os resultados finais apurados, expressos no Guião da auto-avaliação traduzirão, em qualquer caso, a perspectiva da PD - por consenso ou maioria após debate - e não a do avaliador externo.

2.B - Em alternativa (a 2.A) o processo de auto-avaliação é dinamizado por uma equipa/técnico interno.

Pode utilizar-se um "modo de reflexão" que consiste no dinamizador interno propor respostas à Parceria (se possuir elementos sistematizados sobre as matérias em debate). Os resultados finais apurados, expressos no Guião da auto-avaliação traduzirão a opinião da PD - por consenso ou maioria após debate.

Fonte: Auto-avaliação dos Projectos - 2. ${ }^{\mathrm{a}}$ Fase (Gabinete de Gestão EQUAL, 2005). 


\section{Os dispositivos de avaliação dos projectos EQUAL: soluções de operacionalização}

Uma grande parte dos projectos organizou a sua avaliação em alinhamento, mais ou menos próximo, com o modelo geral proposto pelo Guia da auto-avaliação, o qual, segundo a avaliação externa intercalar do Programa (IED, 2005:30), foi bem acolhido pela Parceria como um auxiliar importante para uma mudança de atitudes face à avaliação.

Cada projecto construiu a sua solução avaliativa e as modalidades de aplicação, à medida dos seus interesses e interrogações e das suas competências e recursos, no entendimento de que a avaliação deve beneficiar, antes de mais, os próprios projectos, o seu desempenho, qualidade e consolidação e melhorar a sua capacidade de decisão estratégica. A avaliação não é uma função separada da execução do projecto, tem uma função específica no ciclo de desenvolvimento do pro- jecto, articulando-se com as suas principais etapas de forma a permitir que os resultados sejam utilizados no planeamento da acção.

Com base no Guia, os projectos realizam os exercícios de avaliação, promovendo um debate focalizado nas diferentes etapas do projecto: concepção, operacionalização, realização e impactes, com especial destaque para a avaliação do grau de incorporação e aprofundamento dos "princípios" EQUAL" (transversais a todas as etapas) na prática dos projectos e a sua mais valia para a eficácia da acção, a qualidade dos produtos e da inovação produzida, retirando as devidas conclusões e ilações, identificando os pontos fracos e pontos fortes, para a sua acção presente e futura.

Para além das orientações gerais, relativas à incidência e aos critérios de avaliação, os projectos definiram quais as componentes e as questões de avaliação a valorizar consoante a fase em que se encontravam, os métodos, as técnicas e os instrumentos, os indicadores e as fontes de informação.

Quadro 3 - Incidência, critérios e articulações da Auto-avaliação EQUAL

\begin{tabular}{|c|c|c|c|}
\hline Exercício & Incidência & Critérios & $\begin{array}{c}\text { Articulação com outros } \\
\text { instrumentos }\end{array}$ \\
\hline Inicial & $\begin{array}{l}\text { Concepção } \\
\text { Operacionalização }\end{array}$ & $\begin{array}{l}\text { Pertinência } \\
\text { Coerência interna } \\
\text { e externa } \\
\text { Participação } \\
\text { Coerência interna }\end{array}$ & \\
\hline Intercalar & $\begin{array}{l}\text { Realização } \\
\text { Progressos e resultados }\end{array}$ & $\begin{array}{l}\text { e externa } \\
\text { Eficácia e eficiência } \\
\text { Participação }\end{array}$ & $\begin{array}{l}\text { Avaliação independente e } \\
\text { Validação intercalar de produtos }\end{array}$ \\
\hline Final & $\begin{array}{l}\text { Realização } \\
\text { Resultados } \\
\text { Produtos e práticas inovadoras } \\
\text { Impactes }\end{array}$ & $\begin{array}{l}\text { Eficácia e eficiência } \\
\text { Utilidade } \\
\text { Potencial impacte } \\
\text { Participação }\end{array}$ & $\begin{array}{l}\text { Balanço de Competências final, } \\
\text { Avaliação independente e } \\
\text { Validação final de produtos }\end{array}$ \\
\hline
\end{tabular}

Fonte: Auto-avaliação dos Projectos, Colecção "Saber Fazer" n. 3 (Gabinete de Gestão EQUAL, 2003).

\footnotetext{
${ }^{11}$ Trabalho em parceria, Cooperação transnacional, Empowerment, Igualdade de oportunidades, Inovação e Disseminação.
} 
No primeiro exercício, as $\mathrm{PD}$ revêem e actualizam o estudo da pertinência e da coerência interna e externa do projecto, reavaliando as prioridades, os objectivos e as actividades, a adequação da composição e da organização da parceria, os níveis de incorporação dos princípios EQUAL na Acção 1 e identificam os produtos inovadores;

No exercício intercalar, avalia-se o processo, o desenvolvimento da acção, o progresso dos objectivos, os primeiros resultados conseguidos e os produtos em construção (validação intermédia); os desvios, os problemas e os obstáculos; o modo de funcionamento e gestão da parceria; a intensidade de incorporação e desenvolvimento dos princípios EQUAL e a sua mais valia para a eficácia do projecto e para a produção de inovação. Avalia-se a eficácia e a eficiência e actualiza-se a pertinência e a coerência interna do projecto, sugerindo correcções para melhorar os aspectos menos conseguidos;

No exercício final, focaliza-se sobretudo a identificação e o estudo dos resultados e dos produtos inovadores, a avaliação da eficácia, da eficiência e a análise prospectiva do impacte do projecto; a mais valia e efeito multiplicador dos princípios EQUAL para a produção de inovação; demonstram-se os resultados, as práticas e os produtos inovadores validados e perspectiva-se uma estratégia de disseminação.

\section{Reflexão sobre uma experiência concreta: os méritos e as dificuldades dos exercícios de auto-avaliação}

A experiência da avaliação da primeira fase do EQUAL demonstrou que a avaliação ao nível das PD resultou, em muitos casos, num processo muito mobilizador do conjunto dos parceiros envolvidos nos projectos e terá sido, por isso, um factor de consolidação e reforço da coesão interna da parceria, uma oportunidade de aprendizagem colectiva e um importante contributo para promover o empowerment dos parceiros e dos técnicos. Neste sentido, a avaliação foi um factor de aprendizagem que melhorou o auto-conhecimento das instituições e dos actores nela envolvidos, clarificando várias dimensões essenciais do processo de intervenção: a utilização dos recursos; o progresso dos objectivos e dos produtos; a composição e o funcionamento da parceria; a participação dos destinatários e outros actores relevantes; a incorporação dos princípios EQUAL e sua consequência para a eficácia do projecto e para a sua capacidade de inovar. Pode afirmar-se que a avaliação ao nível das PD cumpre o objectivo estabelecido de melhorar a qualidade das intervenções, tendo-se constituído como um verdadeiro instrumento de gestão e de aprendizagem colectiva, contribuindo para desenvolver uma cultura de diálogo entre os parceiros envolvidos.

Os exercícios de auto-avaliação mais sólidos traduzem uma reflexão mais participada e fundamentada sobre o projecto, os seus resultados e produtos, e resultaram de uma articulação bem sucedida com a avaliação independente, os balanços de competências e a validação de produtos, integrando os respectivos resultados. Segundo a avaliação intercalar do Programa ${ }^{12}$, a qualidade da avaliação das PD conta-se entre os factores que concorrem para a qualidade dos produtos e da inovação produzida, a par de outros factores com ela relacionados, como as dinâmicas de parceria e de empowerment desenvolvidas pelos projectos.

Verificou-se que a qualidade dos exercícios depende do tipo de abordagem das PD: as que assumiram plenamente os princípios EQUAL e foram capazes de os incorporar na sua prática, encaram a avaliação como uma oportunidade, um instrumento e um recurso ao serviço do projecto. Construíram soluções mais criativas e integradas, construíram dispositivos de avaliação mais integrados e retiraram do respectivo processo e dos resultados as devidas ilações para a acção futura no plano estratégico e operacional. Nestes casos, é evidente o impacto dos exercícios de avaliação na melhoria dos projectos e capacitação dos actores neles implicados, cumprindo o seu carácter pedagógico e formativo.

Os exercícios mais modestos são os que se limitaram a um cumprir formal do requisito de auto-avaliar o projecto, encarando o processo como uma mera obrigação e como um obstáculo a

\footnotetext{
12 Estudo de Actualização da Avaliação Intercalar da Intervenção Estrutural de Iniciativa Comunitária EQUAL - Relatório final (coord. Luís Capucha, IED, 2005).
} 
contornar. Um número reduzido de projectos limitou a avaliação ao mero preenchimento dum formulário, como se este fosse mais um procedimento administrativo desligado da dinâmica da parceria e do desenvolvimento do projecto. Daí resultou, em alguns casos, uma avaliação formal, com carácter de "auto-legitimação" (ainda que assente em processos incompletos, inconsistentes e incoerentes), sem qualquer valor acrescentado para o projecto e para todos os que nele estão implicados. Nestes casos foi uma oportunidade perdida, um desperdício de tempo e recursos sem retorno substantivo para a qualidade da intervenção. Os casos menos conseguidos, constituem exercícios segmentados e desarticulados relativamente à aplicação de outros instrumentos, cujos inputs ignoraram.

Uma dificuldade maior de um grande número de projectos relaciona-se com a recomendação de realizar um exercício participado por todos os agentes pertinentes implicados na intervenção. Constatou-se a dificuldade de promover uma ampla participação de todos na reflexão sobre os resultados da avaliação que permitisse clarificar as diferentes perspectivas e construir consensos alargados. Não foram exploradas soluções metodológicas para cruzar todas as fontes e actores pertinentes, deixando de fora pontos de vista essenciais para validar as conclusões da avaliação.

Em particular, a participação dos grupos-alvo das intervenções foi, globalmente, reduzida. Perdeu-se assim uma boa oportunidade para promover activamente o princípio do empowerment para além do âmbito restrito dos parceiros e técnicos envolvidos nos projectos. A interpretação dos resultados de qualquer avaliação não é pacífica e deve considerar a subjectividade dos diferentes actores. Quando tal não acontece obtém- -se uma visão redutora e unilateral dos processos e dos resultados e uma avaliação com fraca representatividade. Numerosas parcerias EQUAL revelaram dificuldade em promover uma avaliação participativa - que ultrapassasse o nível superficial da simples consulta aos grupos alvo - criando as soluções adequadas para que todos tenham um papel activo nas várias fases do processo avaliativo, desde a formulação das questões à apresentação e interpretação dos resultados. Registam-se, no entanto, vários bons exemplos de projectos que construíram soluções criativas e eficazes para incluírem na avaliação os grupos-alvo das acções (técnicas qualitativas, como os focus-grupo e os fóruns de actores, p. ex.).

Uma outra dificuldade, esta quase generalizada, foi a participação dos actores externos às parcerias (actores "institucionais" com interesse e intervenção no âmbito de acção dos projectos), não tendo sido exploradas soluções metodológicas para os envolver.

Na generalidade dos casos, não obstante as insuficiências mencionadas, a auto-avaliação foi mais uma oportunidade que uma dificuldade, mais um recurso do que um obstáculo para os projectos que apostaram nela como um factor de qualidade e de promoção de inovação.

A adesão e as realizações dos projectos EQUAL (da primeira fase) no domínio da avaliação constituem um inegável salto qualitativo na difusão de uma cultura de avaliação e de responsabilidade colectiva. O balanço da experiência é bastante positivo, levanta expectativas elevadas quanto a processos subsequentes (projectos da segunda fase, em execução) e poderá ser passível de disseminação alargada quando os modelos e as soluções adoptadas foram devidamente sistematizadas e validadas com essa finalidade. 


\section{Bibliografia}

COVITA, Horácio, 2003, Recursos Técnico-Pedagógicos \& Práticas Bem Sucedidas, "Saber Fazer" n. ${ }^{\circ}$, Gabinete de Gestão EQUAL, Lisboa.

ESTÊVÃO, Madalena, 2002, Balanço de Competências, "Saber Fazer" n. ${ }^{\circ}$ 1, Gabinete de Gestão EQUAL, Lisboa.

ESTÊVÃO, Madalena, 2005, Balanço de Competências, "Saber Fazer" n. ${ }^{\circ}$ 8, Gabinete de Gestão EQUAL, Lisboa.

GABINETE DE GESTÃO EQUAL, 2004, Guia de Apoio ao Utilizador - 2. ${ }^{a}$ Fase - Programa de Iniciativa Comunitária EQUAL, Lisboa.

GABINETE DE GESTÃO EQUAL (coord.), 2004, Produtos EQUAL: Validar para Disseminar, "Saber Fazer" n. ${ }^{\circ}$, Lisboa.

GABINETE DE GESTÃO EQUAL, 2005, Auto-avaliação dos Projectos - 2. ${ }^{a}$ Fase, "Saber Fazer" n. ${ }^{\circ}$ 5, Gabinete de Gestão EQUAL, Lisboa.
GABINETE DE GESTÃO EQUAL, 2005, Avaliação independente dos Projectos EQUAL - Orientações, Lisboa (policopiado).

GABINETE DE GESTÃO EQUAL (PIMENTA, Manuel, coord.), 2004, Relatório da Auto-avaliação dos Projectos EQUAL - Exercício final - $1 .^{a}$ Fase, Lisboa (policopiado).

IED (CAPUCHA, Luís, coord.), 2005, Estudo de Actualização da Avaliação Intercalar da Intervenção Estrutural de Iniciativa Comunitária EQUAL - Relatório final, IED, Lisboa (policopiado).

INXL (MOURA, Rui coord.), PIMENTA, MANUEL e GABINETE DE GESTÃO EQUAL, 2003, Auto-avaliação dos Projectos, "Saber Fazer" n. ${ }^{\circ}$ 3, Gabinete de Gestão EQUAL, Lisboa.

Página da Internet: www.equal.pt 